\title{
Fibrillin Genes Map to Regions of Conserved Mouse/Human Synteny on Mouse Chromosomes 2 and 18
}

\author{
Xu LI, ${ }^{*}$ Lygia Pereira,$\dagger$ Hu Zhang, $\ddagger$ Chiara Sanguinetı, $\S$ Francesco Ramirez, $\ddagger$ Jeffrey Bonadio, $\S$ \\ AND UTA FRANCKE*, $¥, 1$ \\ *Howard Hughes Medical Institute and TDepartments of Genetics and Pediatrics, Stanford University Medical Center, Stanford, \\ California 94305-5428; †Brookdale Center for Molecular Biology, The Mount Sinai School of Medicine, \\ One Gustave L. Levy Place, New York, New York 10029-6574; and ¥Department of Pathology, \\ University of Michigan Medical Center, Ann Arbor, Michigan 48109-0650
}

Received July 8, 1993; revised September 28, 1993

Fibrillin proteins are major structural components of the 10-nm microfibrils found in elastic and nonelastic connective tissues. Previous studies have mapped the human genes for two fibrillins to chromosome bands $15 q 21$ (FBN1) and 5q23-q31 (FBN2) and have demonstrated that FBN1 mutations are associated with Marfan syndrome, while FBN2 is linked to the gene for congenital contractural arachnodactyly. Here, we report the isolation of genomic clones of the corresponding mouse fibrillin genes (Fbn-1 and $F b n-2)$. By analyzing a mapping panel of mouse $\times$ rodent somatic hybrid cell lines, we have assigned the Fbn-1 gene to mouse chromosome 2 and the Fbn-2 gene to mouse chromosome 18. We then sublocalized the fibrillin genes to bands $2 F$ (Fbn-1) and 18D-E 1 (Fbn-2) by fluorescence in situ hybridization. These regions are known to exhibit conserved synteny with the regions on human chromosomes 15 and 5 that carry the homologous human fibrillin genes. In addition, the Fbn-1 gene maps in the vicinity of the gene for a connective tissue disorder on mouse chromosome 2 called Tight-skin (Tsk). (๑) 1993 Academic Press, Inc.

\section{INTRODUCTION}

Fibrillin represents a newly discovered group of glycoproteins that participates in the formation of extracellular microfibrils (Sakai et al. 1986). The human genes for two fibrillin proteins (FBN1 and FBN2) have previously been characterized (Lee et al., 1991; Maslen et al., 1991; Pereira et al., 1993; Zhang et al., manuscript submitted). Heterozygosity for mutations in the gene coding for the fibrillin-1 protein has been associated with the Marfan syndrome, an autosomal dominant connective tissue disorder with skeletal, cardiac, ocular, and other tissue manifestations that occurs in 1 of 10,000 individuals (Dietz et al., 1991, 1992, 1993; Kainulainen et al., 1992).

\footnotetext{
${ }^{1}$ To whom correspondence should be addressed. Telephone (415) 725-8089. Fax (415) 729-8112.
}

The gene coding for the fibrillin-2 protein (FBN2) has been linked to a rare Marfan-like condition, congenital contractural arachnodactyly (Lee et al., 1991; Tsipouras et al., 1992). However, FBN2 mutations have not yet been identified in patients with this disorder. The two human fibrillin genes, FBN1 and FBN2, are located on chromosomes 15 and 5, respectively (Magenis et al., 1991; Lee et al., 1991)

Comparison of their cDNA sequences indicates that the two fibrillins are structurally related as they display a remarkably similar arrangement of epidermal growth factor-like repeats and TGF $\beta$-binding protein-like domains (Maslen et al., 1991; Lee et al., 1991; Pereira et al., 1993; Zhang et al., manuscript submitted). Preliminary evidence also indicates that the exon/intron organizations of FBN1 and FBN2 are similar, which, in turn, suggests that the fibrillin genes arose from a common ancestral gene.

To gather additional information about the evolution of the fibrillin gene family, we started to clone and map the corresponding genes from other vertebrate species. Here, we report the results of mapping experiments that locate the mouse loci ( $F b n-1$ and $F b n-2)$ to regions of conserved synteny with human chromosomes 15 and 5 . These results corroborate structural evidence that indicates that the mouse fibrillin genes isolated are true homologs of the human genes.

\section{MATERIALS AND METHODS}

Mouse fibrillin genomic clones. Mouse fibrillin genomic clones were isolated by screening a liver DNA library, constructed in the $\lambda$ DASH vector (Stratagene), with human cDNA probes coding for selected portions of the FBN1 (clone F-2.18; Pereira et al., 1993) and FBN2 (clone A06-4; Zhang et al., manuscript in preparation) genes. Hybridization and washing of replica filters were performed under high-stringency conditions. Relevant coding sequences within each of the recombinant phages were identified by Southern blot hybridization to oligonucleotide probes corresponding to specific FBN1 and FBN2 exons and by sequencing the inserts of subclones in pGEM7Z (Promega) vector (Zagursky et al., 1986). Sequences were analyzed using the computer program MacVector (International BioTechnologies Inc.). 

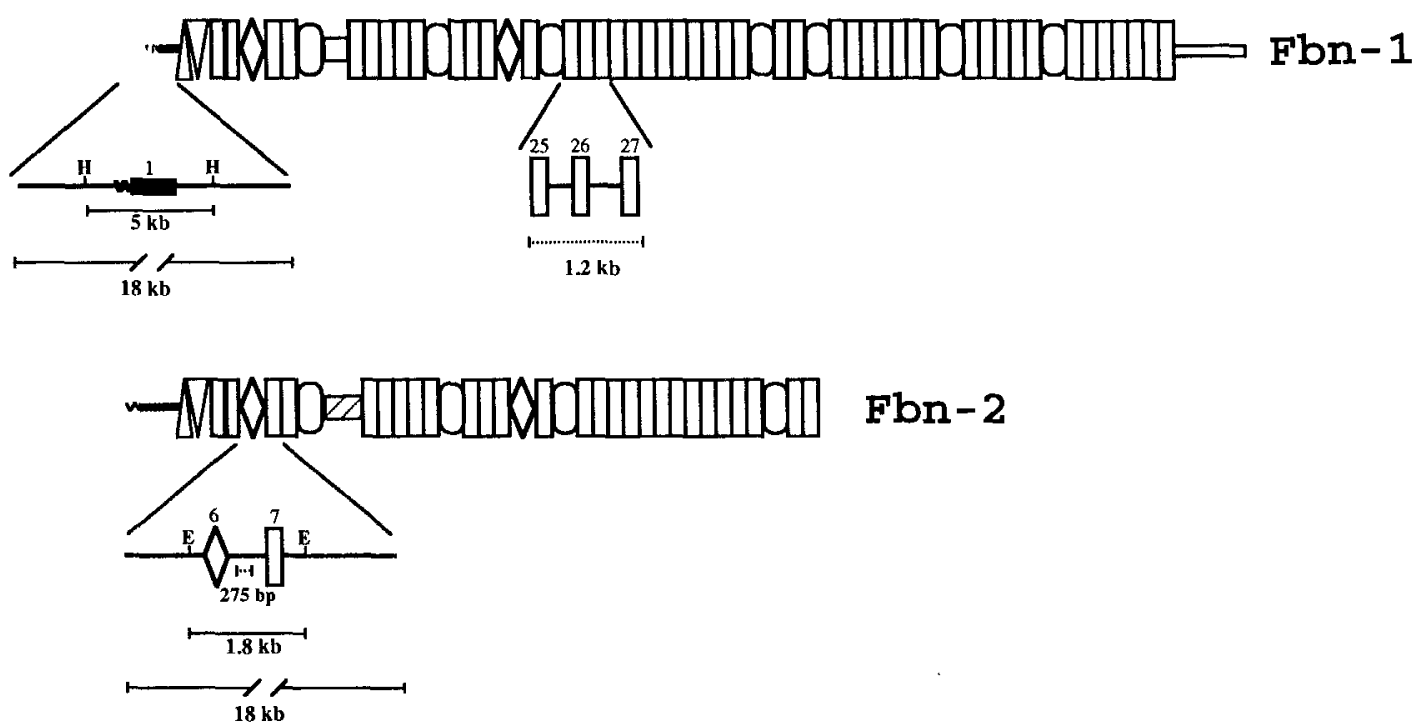

FIG. 1. Schematic representation of the location of the genomic clones ( $18 \mathrm{~kb})$ of the mouse $F b n-1$ and $F b n-2$ genes. Exon numbers and symbols of the different protein motifs are taken from the human FBN1 gene structures (Pereira et al., 1993; Zhang et al., submitted). Coding exons are positioned arbitrarily within the HindIII $(\mathrm{H}-\mathrm{H})$ and $E c o \mathrm{RI}(\mathrm{E}-\mathrm{E})$ subfragments of the genomic clones. The dotted lines identify the Fbn-1 PCR product and the intronic Fbn-2 PCR product that were generated from somatic cell hybrid panels for mapping purposes.

Somatic cell hybrids and PCR amplifications. A mapping panel consisting of 12 mouse $\times$ Chinese hamster and two mouse $\times$ rat somatic cell hybrid lines was used to localize the $\mathrm{Fbn}-1$ and $\mathrm{Fbn}$-2 genes on mouse chromosomes. The hybrids were derived from four independent fusion experiments as described previously (Francke et al., 1977; Francke and Taggart, 1979; Joyner et al., 1985). Based on the organization of the human FBN1 gene (Pereira et al., 1993), PCR primers designed for $F b n-I$ were expected to amplify a $1.2 \mathrm{~kb}$ DNA fragment that contains exons 25,26 , and 27 . The Fbn-1 set of primers was derived from the sequencing of a mouse PCR product amplified from DNA of a mouse $\times$ human somatic cell hybrid panel during the previous mapping of the human gene (Lee et al., 1991). The Fbn-2 set of primers was derived from the sequence of a genomic $1.8-\mathrm{kb} E c o \mathrm{RI}$ subclone and amplified a 275 -bp region of intron 6 . The sequences of the primers (forward/reverse) were as follows: $F b n-1,5^{\prime}$-TCGGCATA GGAGAGGATCTC/5'-GATATCAATGAGTGCAAGATG, and $F b n$ 2 , 5'-CAACGTGTAGGAACCACGAAC $/ 5$-AGAAGACTGTGTG'T GTGCAC. PCR was carried out in a thermal cycler (Perkin-Elmer Cetus) by using the standard protocol provided by the manufacturer. The annealing temperatures and times for each cycle were optimized as follows: for $\mathrm{Fbn}-1,95^{\circ} \mathrm{C}$ for $5 \mathrm{~min}$ and then 35 cycles of $94^{\circ} \mathrm{C}$ for 1 $\min 30 \mathrm{~s}, 55^{\circ} \mathrm{C}$ for $2 \mathrm{~min} 30 \mathrm{~s}$, and $72^{\circ} \mathrm{C}$ for $2 \min$ followed by $72^{\circ} \mathrm{C}$ for $7 \mathrm{~min}$; for $\mathrm{Fbn}-2,95^{\circ} \mathrm{C}$ for $5 \mathrm{~min}$ and then 35 cycles of $94^{\circ} \mathrm{C}$ for $1 \mathrm{~min}$, $55^{\circ} \mathrm{C}$ for $1 \mathrm{~min}$, and $72^{\circ} \mathrm{C}$ for $1 \mathrm{~min}$ followed by extension at $72^{\circ} \mathrm{C}$ for $7 \mathrm{~min}$.

Fluorescence in situ hybridization. The chromosomal locations of the mouse $F b n-1$ and $F b n-2$ genes were independently determined by fluorescence chromosomal in situ hybridization as previously described (Milatovich et al., 1991). Briefly, lambda clones containing genomic sequences of $F b n-1$ and $F b n-2$ were labeled with biotin-11dUTP by nick-translation using commercial reagents (Boehringe Mannheim). Labeled probe was hybridized at a concentration of 100 $200 \mathrm{ng} / 100 \mu \mathrm{l}$ per slide to pretreated and denatured mouse metaphase chromosomes prepared from the mouse cell line Y1-HSR (George and Francke, 1980). Hybridizations were performed in the presence of cold competitor mouse and salmon sperm DNA. After being washed, the slides were covered with avidin/FITC (Vector Laboratories) and amplified using biotinylated goat anti-avidin D antibody (Vector Laboratories) followed by another round of avidin/FITC treatment. Chromosomes were counterstained with $200 \mathrm{ng} / \mu \mathrm{l}$ DAPI (4,6-diamidino-2phenylindole-dihydrochloride) in $2 \times \mathrm{SSC}$. Twenty metaphase spreads were analyzed under an Axiophot (Zeiss) epifluorescence microscope. Signals were counted as specific only when the fluorescent signal was seen on both chromatids of a chromosome. A cooled charge-coupled device camera (Photometrics PM512)/MacIntosh computer system was used for digital imaging, with software supplied by Tim Rand (Yale University). Black and white photographs were generated from PICT files.

\section{RESULTS}

\section{Isolation and Characterization of Mouse Fbn-1 and Fbn-2 Genomic Clones}

During previous cloning work, Lee et al. (1991) obtained distinct murine products from the PCR amplification of somatic cell hybrid DNA using human-specific primers. Comparative exon sequencing revealed a remarkably high level of identity $(\sim 90 \%)$ between the human and murine PCR products. The previous analysis also documented substantial divergence $(\sim 55 \%)$ between the human sequences of FBN1 and FBN2 (Lee et $a l .$, 1991) This preliminary evidence encouraged the at tempt to isolate murine fibrillin genes by using human cDNA probes under stringent screening conditions. Of two $\sim 18$-kb genomic clones identified, one contained sequence corresponding to exon 1 of FBN1, while the other contained sequence corresponding to exons 6 and 7 of FBN2 (Pereira et al., 1993; Zhang et al., manuscript submitted), based on Southern hybridzation to oligonucleotides specific for these exons. Identification of these clones was further confirmed by sequencing a portion of a 5 -kb HindIII subclone of the original $F b n-1$ isolate and a 1.8-kb EcoRI subclone of the original $F b n-2$ phage clone (Fig. 1). Comparative analysis of the nucleotide and translated amino acid sequences again demonstrates a high level of cross-species identity (Fig. 2). Three exons (25-27) were identified in the $1.2-\mathrm{kb}$ long PCR product of $\mathrm{Fbn}-1$ (Fig. 1). As shown in Fig. 2, these exon sequences are also highly conserved between mouse and human FBN1 genes, suggesting that these 


\section{Fbn-1}

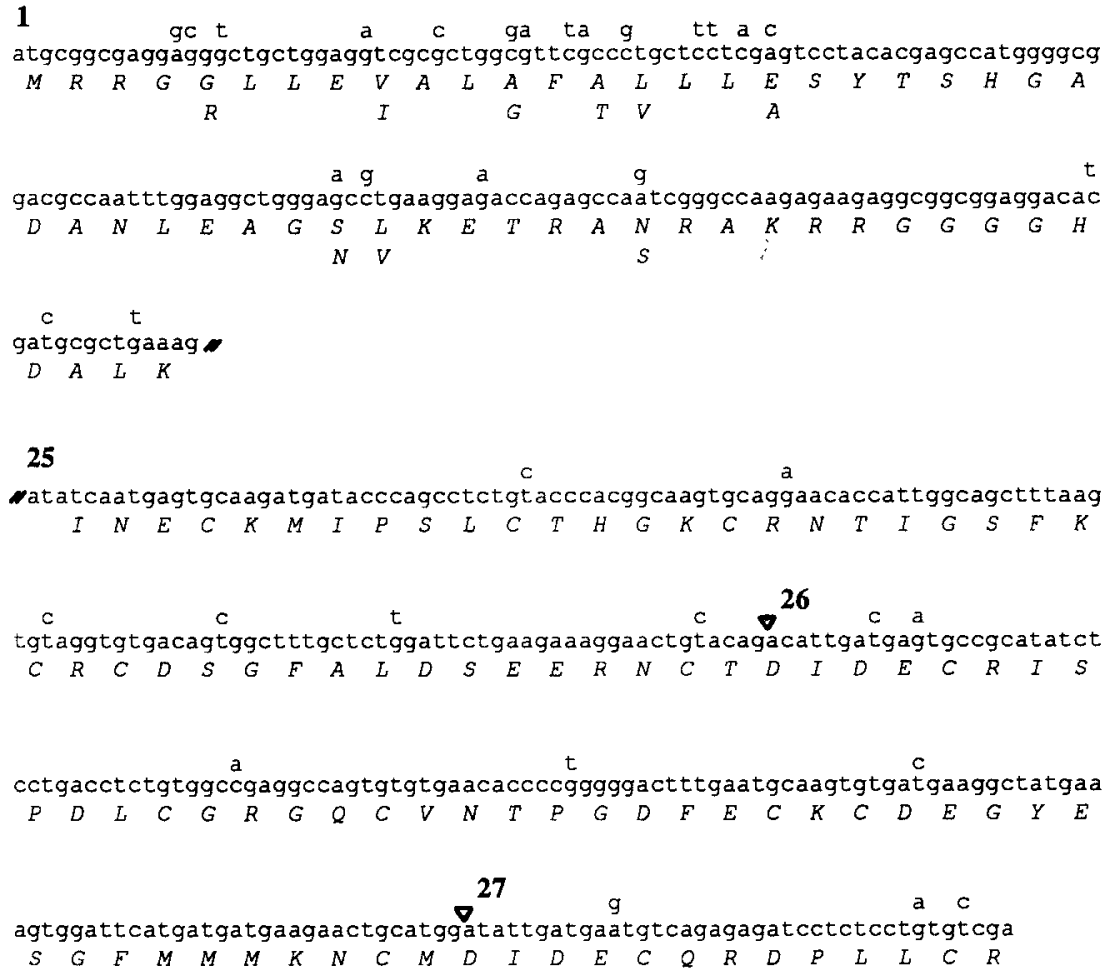

\section{Fbn-2}

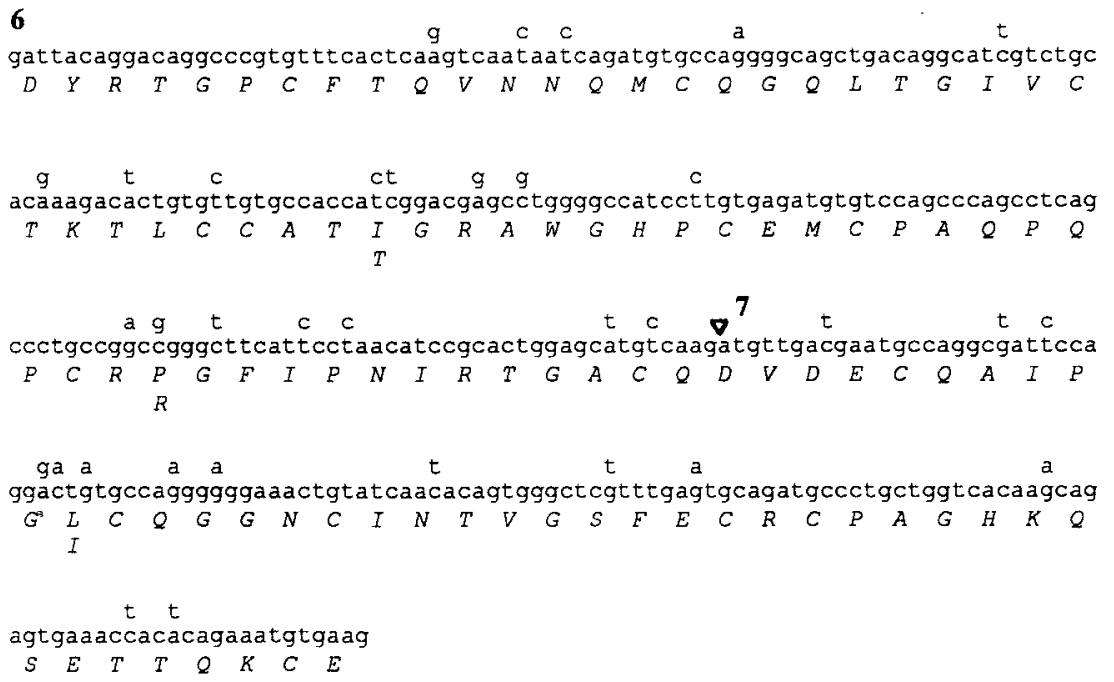

FIG. 2. Sequence of the mouse $F b n-1$ and $F b n-2$ exons shown in Fig. 1 and comparison to the corresponding human sequences (Pereira $e t$ al., 1993; Zhang et al., manuscript submitted for publication). The exon 1 sequence of $F b n-1$ is limited to its coding portion. Numbers in bold indicate the positions of exons, and inverted triangles illustrate splicing junctions. The mismatched nucleotides and amino acids of human sequences are shown above and below the mouse sequences, respectively.

genes are probably organized in a similar, if not identical, fashion.

Assignment of Fbn-1 to Mouse Chromosome 2

Genomic DNA from a panel of 14 mouse $\times$ rodent hybrid cell lines was analyzed by PCR using primers that specifically amplified $F b n-1$ sequences. The expected 1.2-kb PCR product containing exons $25-27$ as well as intron sequences was obtained from hybrid cell lines that had retained mouse chromosome 2, including a hybrid line containing only mouse chromosome 2 , and from two controls, a genomic Fbn-1 clone and mouse 
TABLE 1

Comparison of Mouse Fbn-1 Sequences with Mouse Chromosomes in Rodent $\times$ Mouse Somatic Cell Hybrids

\begin{tabular}{|c|c|c|c|c|c|c|c|c|c|c|c|c|c|c|c|c|c|c|c|c|}
\hline \multirow{2}{*}{$\begin{array}{l}F b n-1 \text { signal/ } \\
\text { chromosome }\end{array}$} & \multicolumn{20}{|c|}{ Mouse chromosome } \\
\hline & 1 & 2 & 3 & 4 & 5 & 6 & 7 & 8 & 9 & 10 & 11 & 12 & 13 & 14 & 15 & 16 & 17 & 18 & 19 & $\mathrm{X}$ \\
\hline \multicolumn{21}{|l|}{ Discordant hybrids } \\
\hline$+1-$ & 4 & 0 & 4 & 3 & 6 & 4 & 2 & 4 & 7 & 6 & 10 & 3 & 5 & 5 & 3 & 5 & 2 & 5 & 2 & 4 \\
\hline$-/+$ & 2 & 0 & 0 & 0 & 0 & 2 & 1 & 0 & 2 & 2 & 2 & 3 & 2 & 0 & 2 & 2 & 2 & 0 & 0 & 2 \\
\hline \multicolumn{21}{|l|}{ Concordant hybrids } \\
\hline$-/-$ & 1 & 4 & 4 & 4 & 3 & 2 & 3 & 4 & 2 & 2 & 2 & 1 & 2 & 4 & 2 & 2 & 2 & 4 & 3 & 2 \\
\hline Informative hybrids & 13 & 14 & 14 & 13 & 12 & 12 & 14 & 14 & 14 & 13 & 14 & 13 & 13 & 14 & 14 & 13 & 14 & 13 & 13 & 13 \\
\hline$\%$ discordance & 46 & 0 & 29 & 23 & 50 & 50 & 21 & 29 & 64 & 54 & 86 & 46 & 54 & 36 & 36 & 54 & 29 & 38 & 15 & 46 \\
\hline
\end{tabular}

Note. Data for chromosomes with rearrangements or present at low copy $(<0.1)$ were excluded. The \% discordance is calculated as the sum of discordant over total informative hybrids on each chromosome.

3T3 DNA. Under these PCR conditions, no specific amplification was seen with Chinese hamster DNA as template, and a differently sized PCR product was generated from rat DNA. As shown in Table 1, all mouse chromosomes were excluded by this panel except chromosome 2 , which had no discordance. 'These results indicated that the $F b n-1$ gene is located on mouse chromosome 2 .

Fluorescence in situ hybridization confirmed the $\mathrm{Fbn}$ 1 assignment to chromosome 2 and refined the physical map position. A specific fluorescent signal on both chromatids of chromosome 2 was seen in 13 of 20 metaphase cells analyzed. Based on a weak banding pattern produced by DAPI staining and the relative distance of the signal from the centromere and telomere, the Fbn-1 locus was assigned to band $\mathrm{F}$ on chromosome $2(2 \mathrm{~F})$ (Figs. 3A and 4).

\section{Assignment of Fbn-2 to Mouse Chromosome 18}

The same panel of hybrid cell lines was analyzed by PCR using primers that specifically amplify $F b n-2$ se- quence. As summarized in Table 2, the presence or absence of mouse chromosome 18 in hybrid cell lines was in complete concordance with the $\mathrm{Fbn}-2$ signal. All other mouse chromosomes were excluded by at least $23 \%$ discordant hybrids.

Fluorescence in situ hybridization using Fbn-2 genomic DNA as a probe localized the $F b n-2$ gene to a region corresponding to bands D-E1 of mouse chromosome 18. Of 20 metaphase spreads examined, 6 had a signal on both chromatids at this location on one 18 homolog and 10 had specific signals on both chromosomes 18 (Figs. $3 \mathrm{~B}$ and 4).

\section{DISCUSSION}

Comparative mapping of homologous genes on human and mouse chromosomes represents a powerful tool for studying the evolution of genome organization and for identifying candidate genes for genetic disorders. Accordingly, in this study, we determined the chromosomal
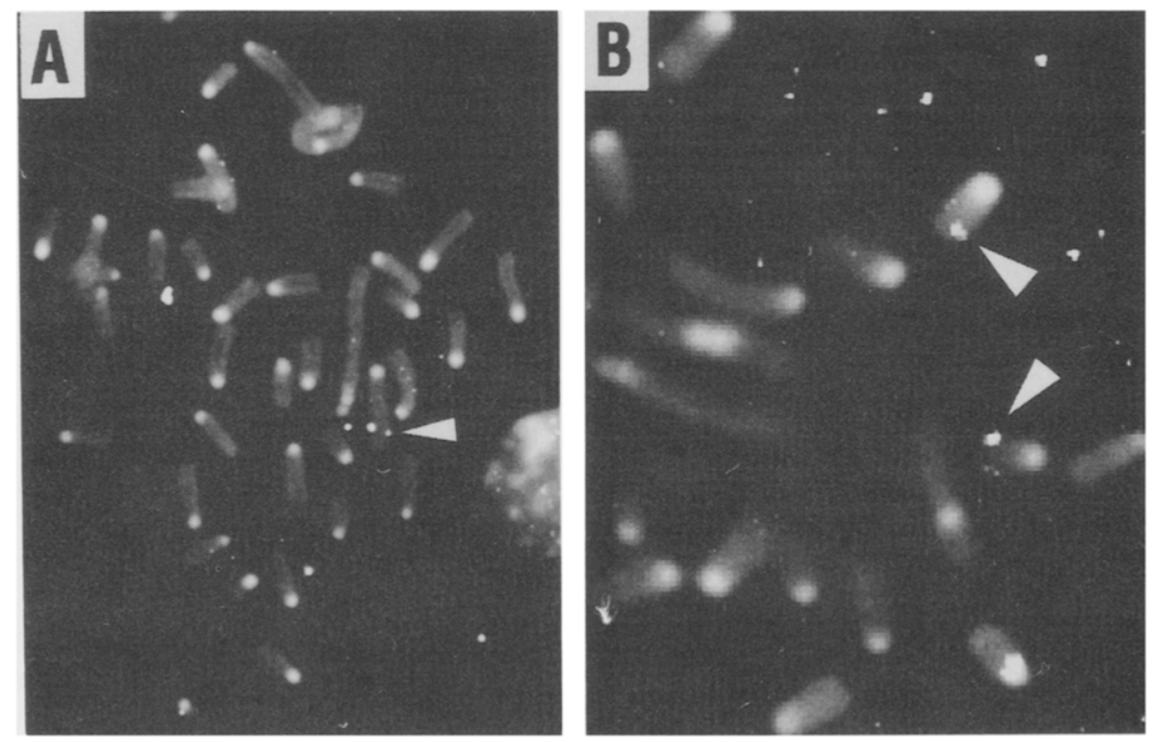

FIG. 3. Chromosomal mapping of (A) Fbn-1 and (B) Fbn-2 by fluorescence in situ hybridization. A double chromatid signal is present on chromosome $2(F b n-1)$ at a site corresponding to band $\mathrm{F}$ and on chromosome $18(F b n-2)$ at a location corresponding to bands D-E1 (indicated by arrowheads). 


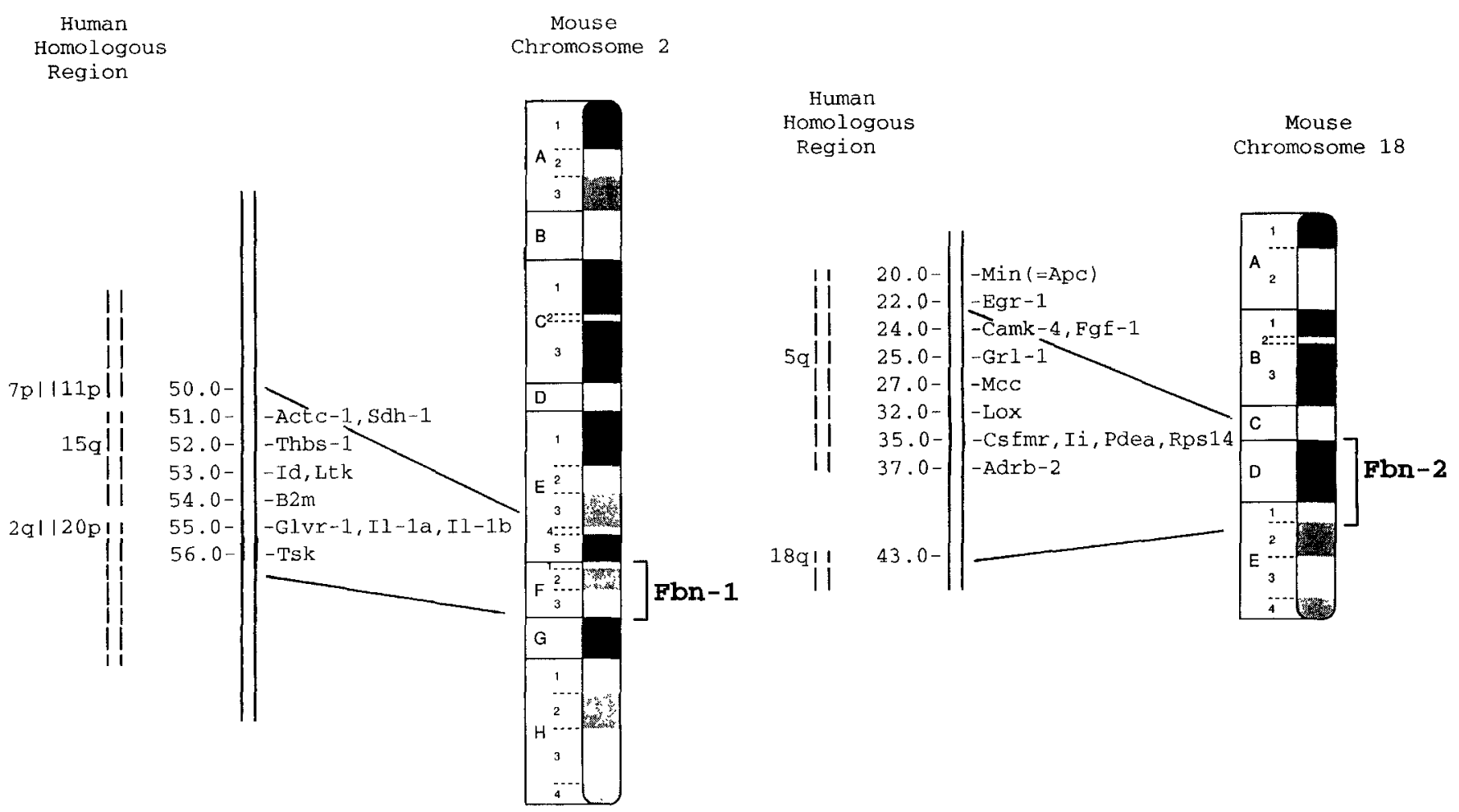

FIG. 4. Idiograms of mouse chromosomes 2 and 18 (Nesbitt and Francke, 1973), illustrating the localizations of $F b n-1$ and $F b n-2$ (indicated by brackets), and other loci in the conserved regions (from Lyon and Kirby, 1993, depicted by a double solid line), as well as the human homologous chromosome regions (double dashed lines).

location of the murine genes encoding the counterparts of the two human fibrillin proteins. The identification of the mouse clones, initially based on the high level of exon sequence identity to the human genes, was corroborated by the mapping data presented in this paper, which were obtained by two independent and complementary strategies: somatic cell hybrid panel analysis and fluorescence in situ hybridization to metaphase chromosomes.

The $F b n-1$ gene was found to reside on chromosome 2, band $2 \mathrm{~F}$. A segment on mouse chromosome 2 comprising bands E4-F (corresponding to region 51-54 cM on the genetic map) (Lyon and Kirby, 1993) has been identified to contain genes that are homologous to human genes assigned to human chromosome region 15q13-q21 (Fig. 4). These include the genes for cardiac muscle $\alpha$-actin
(Actc-1), sorbitol dehydrogenase-1 ( $S d h-1), \beta$-2-microglobulin $(B 2 m)$, limb deformity (formin) (ld), leukocyte tyrosine kinase $(L t k)$, and thrombospondin (Thbs-1) (summarized by Lyon and Kirby, 1993). The human FBN1 gene at 15q21.1 and the murine Fbn-1 locus at $2 \mathrm{~F}$ add another pair of homologous loci to this conserved syntenic region.

We have assigned the murine $F b n-2$ locus to chromosome 18 in a region corresponding to bands D-E1. On mouse chromosome 18 , the central region $B-D$ contains many genes that have homologs on human chromosome 5 in region q21-q34 (Fig. 4). On the genetic map, the minimal conserved homologous region extends from the familial adenomatous polyposis locus ( $\mathrm{in}, A p c)$ at 20 $\mathrm{cM}$ to the gene for the $\beta-2$ adrenergic receptor $(A d r b-2)$

TABLE 2

Comparison of Mouse Fbn-2 Sequences with Mouse Chromosomes in Rodent $\times$ Mouse Somatic Cell Hybrids

\begin{tabular}{|c|c|c|c|c|c|c|c|c|c|c|c|c|c|c|c|c|c|c|c|c|}
\hline \multirow{2}{*}{$\begin{array}{l}F b n-2 \text { signal/ } \\
\text { chromosome }\end{array}$} & \multicolumn{20}{|c|}{ Mouse chromosome } \\
\hline & 1 & 2 & 3 & 4 & 5 & 6 & 7 & 8 & 9 & 10 & 11 & 12 & 13 & 14 & 15 & 16 & 17 & 18 & 19 & $\mathrm{X}$ \\
\hline \multicolumn{21}{|l|}{ Discordant hybrids } \\
\hline$+/-$ & 1 & 0 & 2 & 0 & 2 & 1 & 1 & 1 & 3 & 2 & 4 & 0 & 1 & 2 & 1 & 2 & 1 & 0 & 0 & 3 \\
\hline$-/+$ & 5 & 6 & 4 & 3 & 2 & 4 & 6 & 3 & 4 & 3 & 2 & 5 & 4 & 3 & 6 & 5 & 7 & 0 & 4 & 7 \\
\hline \multicolumn{21}{|l|}{ Concordant hybrids } \\
\hline$-1-$ & 4 & 4 & 6 & 7 & 7 & 5 & 4 & 7 & 6 & 6 & 8 & 5 & 6 & 7 & 4 & 5 & 4 & 9 & 5 & 3 \\
\hline Informative hybrids & 13 & 14 & 14 & 13 & 12 & 13 & 14 & 14 & 14 & 13 & 14 & 14 & 13 & 14 & 14 & 13 & 14 & 13 & 13 & 13 \\
\hline$\%$ discordance & 46 & 43 & 43 & 23 & 33 & 38 & 50 & 29 & 50 & 38 & 43 & 36 & 38 & 36 & 50 & 54 & 57 & 0 & 31 & 77 \\
\hline
\end{tabular}

Note. Data for chromosomes with rearrangements or present at low copy $(<0.1)$ were excluded (see legend to Table 1$)$. 
at $37 \mathrm{cM}$ and includes Egr-1, Fgf-1, Camk-4, Gril-1, Mcc, Lox, Ia-associated invariant chain (Ii), cGMP-phosphodiesterase alpha (Pdea), ribosomal protein S14 (Rps14), and colony stimulating factor-1 receptor (Csfmr) (summarized by Lyon and Kirby, 1993). With human FBN2 previously assigned to 5q23-q31 (Lee et al., 1991), our assignment of $\mathrm{Fbn}-2$ to a region of mouse 18 corresponding to bands D-E1 clearly places this locus into the conserved region.

Interestingly, the phenotypic locus Tight-skin (Tsk) has been assigned to mouse chromosome 2 band $\mathrm{F}$, at 56 $\mathrm{cM}$ on the consensus linkage map, $2 \mathrm{cM}$ distal to $B 2 m$, a gene on the most distal part of the human $15 \mathrm{q}$ homologous region (Fig. 4). Tsk arose spontaneously in the B10.d2 $(58 \mathrm{~N})$ mouse strain and is inherited in a semidominant fashion. Heterozygotes have tight skin as early as 1 week after birth, while homozygotes die early during embryogenesis. Phenotypically, Tsk mice are characterized by excessive growth of connective tissue and skeleton, large accumulations of microfibrils in the intercellular spaces, increased procollagen content of the skin, and emphysema (Green et al., 1976; Jiminez et $a l$., 1986). Since our mapping data of $F b n-1$ do not exclude $T s k$ as a candidate mutation, it may be worthwhile to analyze fibrillin synthesis and deposition in Tsk heterozygotes. We do not mean to propose $T s k$ as a mouse model for Marfan syndrome (MFS), although identical mutations may produce quite different phenotypes in mice and humans. Alternatively, the type of mutation could be important. Even though FBN1 nonsense and certain missense mutations have been documented in individuals with MFS (Dietz et al., 1991, 1992), other FBN1 mutations could conceivably result in quite different phenotypes.

\section{ACKNOWLEDGMENTS}

The authors thank Mr. K. Andrikopoulos for the generous gift of the mouse genomic library. This work was supported by NIH Grants HG00298 (U.F.), AR40679 (J.B.), and AR42044 (F.R.) and the Howard Hughes Medical Institute, of which U.F. is an investigator and X.L. is an associate. This is article 135 from the Brookdale Center for Molecular Biology.

\section{REFERENCES}

Dietz, H. C., Cutting, G. R., Pyeritz, R. E., Maslen, C. L., Sakai, L. Y., Corson, G. M., Puffenberger, E. G., Hamosh, A., Nanthakumar, E. J., Curristin, S. M., Stetten, G., Meyers, D. A., and Francomano, C. A. (1991). Marfan syndrome caused by a recurrent de novo missense mutation in the fibrillin gene. Nature 352:337-339.

Dietz, H. C., Pyeritz, R. E., Puffengerger, E. G., Kendzior, R. T., Jr., Corson, G. M., Maslen, C. L., Sakai, L. Y., Francomano, C. A., and Cutting, G. R. (1992). Marfan phenotype variability in a family segregating a missense mutation in the epidermal growth factor-like of the fibrillin gene. J. Clin. Invest. 89:1674-1680.

Dietz, H. C., Valle, D., Francomano, C. A., Kendzior, R. J., Pyeritz, R. E., and Cutting, G. R. (1993). The skipping of constitutive exons in vivo induced by nonsense mutations. Science 259:680-683.

Francke, U., Lalley, P. A., Moss, W., Ivy, J., and Minna, J. D. (1977).
Gene mapping in Mus musculus by interspecies cell hybridization: Assignment of the genes for tripeptidase- 1 to chromosome 10 , dipeptidase-2 to chromosome 12 , and adenylate kinase-1 to chromosome 2. Cytogenet. Cell Genet. 19:57-84.

Francke, U., and Taggart, R. T. (1979). Assignment of gene for cytoplasmic superoxide dismutase (Sod-1) to a region of chromosome 16 and of Hprt to a region of the $\mathrm{X}$ chromosome in the mouse. Proc. Natl. Acad. Sci. USA 76:5230-5233.

George, D. L., and Francke, U. (1980). Homogeneously staining chromosome regions and double minutes in a mouse adrenocortical tumor cell line. Cytogenet Cell Genet. 28:217-226.

Green, M. C., Sweet, H. O., and Bunker, L. E. (1976). Tight-skin, a new mutation of the mouse causing excessive growth of connective tissue and skeleton. Am. J. Pathol. 82:493-512.

Jiminez, S. A., Williams, C. J., Myers, J. C., and Bashey, R. I. (1986). Increased collagen biosynthesis and increased expression of type I and type III procollagen genes in tight skin (TSK) mouse fibroblasts. J. Biol. Chem. 261:657-662.

Joyner, A. C., Lebo, R. V., Kan, Y. W., Tjian, R., Cox, D. R., and Martin, G. R. (1985). Comparative chromosome mapping of a conserved homeo box region in mouse and human. Nature 314:173. 175 .

Kainulainen, L., Sakai, L. Y., Child, A., Pope, F. M., Puhakka, L., Ryhanen, L., Palotie, A., Kaitila, I., and Peltonen, L. (1992). Two unique mutations in Marfan syndrome resulting in truncated polypeptide chains of fibrillin. Proc. Natl. Acad. Sci. USA 88:59175921.

Lee, B., Godfrey, M., Vitale, E., Hori, H., Mattei, M. G., Sarfarazim, M., Tsipouras, P., Ramirez, F., and Hollister, D. W. (1991). Linkage of Marfan syndrome and a phenotypically related disorder to two different fibrillin genes. Nature 352:330-334.

Lyon, M. F., and Kirby, M. C. (1993). Mouse chromosome atlas. Mouse Genome 91 : 40-80.

Magenis, R. E., Maslen, C. L., Smith, L., Allen, L., and Sakai, L. Y. (1991). Localization of the fibrillin (FBN) gene to chromosome 15, band q21.1. Genomics 11:346-351.

Maslen, C. L., Corson, G. M., Maddox, B. K., Glanville, R. W., and Sakai, L. Y. (1991). Partial sequence of a candidate gene for the Marfan syndrome. Nature 352:334-337.

Milatovich, A., Travis, A., Grosschedl, R., and Francke, U. (1991). Gene for lymphoid enhancer-binding factor 1 (LEF1) mapped to human chromosome $4(q 23-\dot{q} 25)$ and mouse chromosome 3 near Egf. Genomics 1 1:1040-1048.

Nesbitt, M. N., and Francke, U. (1973). A system of nomenclature for band patterns of mouse chromosome. Chromosoma 41:145-158.

Pereira, L., D’Alessio, M., Ramirez, F., Lynch, J. R., Sykes, B., Pangilinan, T., and Bonadio, J. (1993). Genomic organization of the sequence coding for fibrillin, the defective gene product in Marfan syndrome. Hum. Mol. Genet. 2:961-968.

Sakai, L. Y., Keene, D. R., and Engvall, E. (1986). Fibrillin, a new $350-\mathrm{kD}$ glycoprotein, is a component of extracellular microfibrils. $J$. Cell Biol. 103:2499-2509.

Tsipouras, P., Mastro, R. B., Sarfarazi, M., Lee, B., Vitale, E., Child, A. H., Godfrey, M., Devereux, R. B., Hewett, D., Steinman, B., Viljoen, D., Sykes, B. C., Kilpatrick, M., Ramirez, F., and The International Marfan Syndrome Collaborative Study. (1992). Genetic linkage of the Marfan syndrome, ectopia lentis, and congenital contractural arachnodactyly to the fibrillin genes on chromosomes 15 and 5. N. Engl. J. Med. 326:905-909.

Zagursky, R. J., Berman, M. L., Baumister, K., and Lomas, N. (1986). Rapid and easy sequencing of linear double stranded DNA and supercoiled plasmid DNA. Gene Anal. Technique 2:89-94.

Zhang, H., Apfelroth, S. D., Hu, W., Davis, E. C., Sanguineti, C., Bonadio, J., Mecham, R. P., and Ramirez, F. (1994). Structure and expression of fibrillin-2, a novel microfibrillar component preferentially expressed in elastic matrices, submitted for publication. 